\title{
Simulation-based learning and assessment for hospital pharmacy service experience among final year pharmacy students in Malaysia
}

\author{
N.I.M. Nazar*, M.H. Elnaem, N.S.A. Rahman \\ Department of Pharmacy Practice, Kulliyyah of Pharmacy, International Islamic University Malaysia, Malaysia
}

\author{
Keywords \\ Experiential Learning Methods \\ Assessment \\ Malaysia \\ ${ }^{*}$ Corresponding author \\ norilyani@iium.edu.my
}

\author{
Summary \\ This case study reports on the simulation-based learning initiative to replace \\ experiential learning in an actual hospital pharmacy setting, namely Outpatient and \\ Inpatient Pharmacy Services. The report describes the teaching and learning as well as \\ the assessment components given to the students in a Malaysian setting.
}

\section{Background and Context}

During the COVID-19 pandemic and the Movement Control Order by the Malaysian government, the students were unable to proceed with their hospital pharmacy attachment for experiential learning. The Kulliyyah of Pharmacy, International Islamic University Malaysia (IIUM), has adopted simulation-based learning (SBL) to provide a similar experience to the students whilst still achieving the desired learning outcomes. SBL is one of the learning techniques which has been extensively used in healthcare education, with varying degrees of skill features and technological applications. Simulation is a technique for practice and learning that can be applied to many different disciplines and trainees. It is a technique (not a technology) which can replace or amplify real experiences with guided ones, often 'immersive' in nature, that evoke or replicate substantial aspects of the real world in a fully interactive fashion. SBL can be a way to develop health professionals' knowledge, skills, and attitudes, whilst protecting patients from unnecessary risks (Veettil, \& Rajiah, 2016).

In pharmacy education, SBL is used to facilitate clinical skills development, professionalism and ethics, interpersonal relationship, dispensing skills, optimal use of medicines, drug information, self-directed learning, problem-based learning competency-based assessment as well as enhancing learning through feedback and reflection (Lateef, 2010). With the nature of SBL, it allows students to respond to high-risk situations, but in a safe environment. In the case of this pandemic, the definition of 'safe environment' is not only in avoiding patient inconvenience or putting them at risk, but it can also be extended to the safe environment for the learners.

\section{Educational Description}

For the teaching and learning component, the students were divided into several groups before the virtual attachment, with a maximum number of five students per group. Each group was assigned to one preceptor among the faculty members. The purpose of the arrangement was to increase the level of engagement with the preceptors and at best simulated the real-life experience of hospital pharmacy services attachment. The services involved were Outpatient and Inpatient Pharmacy Services. These two departments were chosen because the roles of pharmacists are heavily distributed within these two departments.

The desired learning outcomes that needed to be achieved by the students were that they should be able to demonstrate the role of pharmacist in practicing pharmaceutical care, 
counselling and monitoring alongside the delivery of therapeutic management; delivering various pharmacy services in an inter-professional environment; and effectively communicating with patients, patients' carers and other healthcare professionals in the delivery of pharmaceutical care.

Prescription handling has been identified as the central component of this SBL. In total, there were 50 prescriptions (for both Inpatient and Outpatient) of various disease conditions that have been created with some adaptations from actual cases retrieved from the teaching hospital for the students' experiential learning. The patients' identification was kept confidential and only the disease and the list of medications were used. The prescriptions were purposely created as problematic and the students needed to proceed with the step-by-step approach of prescription handling from receiving, screening, filling, labelling, counterchecking, dispensing, and counselling. Out of these 50 prescriptions, five prescriptions were assigned and simulated to the students every week for assessment. The students needed to discuss the exercises at least twice a week in consultation with their preceptors. The students were also exposed to the drug distribution system where they needed to prepare their medication slots to simulate medication supply. Students also learnt about the process of handling psychotropics and dangerous drug substances for both inpatient and outpatient pharmacy settings.

The students were also provided with other teaching and learning materials, which included video demonstrations on the roles of pharmacists at the Outpatient and Inpatient Pharmacy, as well as guidelines from the Ministry of Health Malaysia for them to familiarise themselves with. There were also various web-based references given to the students, such as McGraw Hill Database.

For the assessments, various activities had been conducted such as video presentation, in person sessions, objective structured clinical examinations (OSCEs) and a closed-book final assessment. From the prescriptions assigned to them they were asked to prepare two videos, which were:

1. Counselling demonstration and

2. Extemporaneous preparation techniques.

For the counselling video, they needed to, as much as possible, simulate the actual pharmacy setting using their family members. The same applied for extemporaneous preparation videos. At the end of every rotation, the students needed to attend a face-to-face session with their preceptor for feedback and discussion.

\section{Outcomes and Recommendations}

Though the simulated experience will never replace the actual experiential learning, it is expected to become extensively used during the pandemic lockdown situation. From the assessment the students were, in general, able to achieve the desired learning outcomes. However for future improvement, it is highly recommended to include the interprofessional learning component in the simulation exercise and assessment. The main challenge faced was to maintain the students' levels of participation and engagement during the synchronous sessions.

\section{References}

Lateef, F. (2010). Simulation-based learning: Just like the real thing. Journal of emergencies, trauma, and shock, 3(4), 348-352. https://doi.org/10.4103/0974-2700.70743

Veettil, S.K., \& Rajiah, K. (2016). Use Of Simulation In Pharmacy Practice And Implementation In Undergraduate Pharmacy Curriculum In India. International Journal of Pharmacy and Pharmaceutical Sciences, 8(7), 1-5. Available at: https:// innovareacademics.in/journals/index.php/ijpps/article/view/8262 